Fanum

Sociológico

\section{Forum Sociológico}

Série II

$24 \mid 2014$

Circulação de saberes e desafios em saúde

\title{
Os desafios dos saberes na investigação em saúde
}

The challenges of knowledge in health research

\section{Graça Carapinheiro}

\section{OpenEdition}

Journals

\section{Edição electrónica}

URL: https://journals.openedition.org/sociologico/985

DOI: 10.4000/sociologico.985

ISSN: 2182-7427

\section{Editora}

CICS.NOVA - Centro Interdisciplinar de Ciências Sociais da Universidade Nova de Lisboa

\section{Edição impressa}

Paginação: 13-18

ISSN: 0872-8380

\section{Refêrencia eletrónica}

Graça Carapinheiro, "Os desafios dos saberes na investigação em saúde», Forum Sociológico [Online], 24 | 2014, posto online no dia 01 novembro 2014, consultado o 30 março 2022. URL: http:// journals.openedition.org/sociologico/985 ; DOI: https://doi.org/10.4000/sociologico.985

Este documento foi criado de forma automática no dia 30 março 2022

(c) CICS.NOVA 


\title{
Os desafios dos saberes na investigação em saúde ${ }^{1}$
}

\author{
The challenges of knowledge in health research
}

\author{
Graça Carapinheiro
}

1 Proponho-me pensar convosco algumas das questões que têm vindo a assumir um caráter crucial e estratégico para a pesquisa em saúde, pondo provisoriamente de parte toda a discussão epistemológica e metodológica que envolve a separação, se é que ela existe de uma forma tão nítida e vincada, entre pesquisa qualitativa e pesquisa quantitativa.

2 Para os propósitos deste congresso e do tema que os subscreve, "Circulação de Saberes e Desafios em Saúde", importa debruçarmo-nos sobre o que está subjacente à investigação em saúde, ou seja, a aproximação entre domínios de conhecimento e formas de saber que historicamente nasceram em tempos desiguais, se autonomizaram segundo racionalidades científicas específicas e particulares e se institucionalizaram a partir da construção de hierarquias de reconhecimento e legitimação da estratificação do prestígio social que têm vindo a conferir posições de valor desigual entre as ciências que se debruçam sobre a saúde, a doença e as medicinas ao longo dos tempos, o que foi examinado por vários autores quando se debruçaram sobre os espaços, tempos e processos que transcorrem entre a emergência dos dispositivos do Bio-Poder e a consolidação do Poder Médico (Carapinheiro, 2005).

3 A posição dominante e hegemónica que se tem atribuído à Medicina ocidental que nasceu na Europa tem vindo a ser pautada por dimensões normativas, reguladoras e de controlo e disciplina social que na relação com as ciências que se interessam pela saúde e pela doença, e que também fazem destas matérias o seu objeto central de pesquisa, como é o caso das Ciências Sociais e Humanas, lhes tem conferido, persistentemente, posições subalternas, ainda que com contornos e traços diferenciados de acordo com a história destas ciências em cada sociedade e em cada região do mundo.

4 Sintetizando de forma abrangente este olhar retrospetivo, estamos situados num tempo histórico em que terrenos progressivamente mais alargados de análise estão sob a 
auscultação científica de um campo cada vez mais heterogéneo e diversificado de agendas políticas, quer as das políticas públicas, quer as das políticas de saúde, quer as das políticas da vida, nas inúmeras derivações da medicalização das sociedades, através da sua progressiva e inevitável normatividade biológica, a partir do poder e da influência que adquiriu o conhecimento da genética e ainda por força da ininterrupta reconversão farmacológica dos recursos globais de saúde, no que é amplamente reconhecido como a crescente farmacologização e geneticização das sociedades (Mendes, 2007; Lopes, 2010; Carapinheiro, 2007).

5 Se desde a fundação da medicina como ciência experimental e positiva atravessarmos os séculos em que a passagem da descoberta dos mistérios insondáveis do que se escondia dentro do corpo e do que se encerrava dentro da alma, para o conhecimento dos órgãos e da sua fisiologia, das células e da sua estrutura nuclear, até aos genes e à sua configuração biomolecular, vemos desenrolar-se a construção de um vasto campo de conhecimento,

6 inicialmente, numa 1. ${ }^{a}$ fase, titubeante e vulnerável, sobre a definição das matérias a considerar como estritamente médicas e as primeiras tentativas de codificação das suas realidades clínicas.

7 seguidamente, numa 2. fase, triunfal e consagrada (como a denominada teoria dos germes),

8 depois, numa 3." fase, heróica e maldita (refiro-me à descoberta de novas substâncias analgésicas, anestésicas e antibióticas e de novas técnicas cirúrgicas, antes, durante e após as duas Guerras Mundiais, embora concomitantemente cúmplice na exploração do horror humano nas práticas de eugenismo, de segregacionismo e de perseguição),

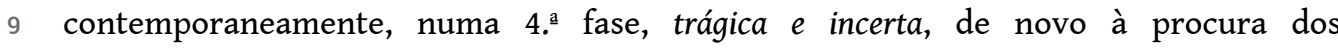
pressupostos que fundamentam a evidência científica, a denominada Evidence Based Medicine (EBM) (Sackett, Rosenberg, Muir Gray, Haynes, Richardson, 1996), cuja oportunidade é necessário interpretar face à deriva da incerteza, do risco e da falência, originada pela complexidade das doenças crónicas, das doenças degenerativas e das doenças infeciosas e virais, mais ou menos rapidamente letais, e face à correlativa espiral das ondas de sofrimento humano que se expandiram e acentuaram, segundo novas formas de viver a experiência humana da doença e do adoecimento.

Quer dizer que a corrente de fundo positivista, que forjou a filosofia científica de lidar com as inquietações e aflições humanas ligadas à saúde, à doença, à dor e ao sofrimento, sempre se ancorou sem barreiras no raciocínio médico, de caráter individualista e casuístico, mesmo quando, com o recurso a novos conhecimentos especializados e hiperespecializados e a novos meios de diagnosticar e tratar, a procura dessas evidências se converteu em encarniçamento terapêutico, com sucessivos arranjos em que os riscos se sobrepuseram à confiança clínica, em que a iatrogenia atingiu o seu clímax, de onde têm emergido novas formas de incapacitação e estigmatização, bem como novos dilemas e implicações éticos no manuseamento de um arcabouço de conhecimento que, apesar do seu volume e sofisticação, parece não conseguir conduzir-nos à experiência contemporânea de viver a saúde e a doença com mais qualidade, com mais segurança e com mais equidade e justiça, tal como estava traçado na sua visão prometeica original.

11 Além disso, a crescente complexidade da gestão da dor e da organização terapêutica dos cuidados continuados e paliativos tem vindo a reclamar qualificações mais exigentes, 
capazes de reformular e inovar as competências de todos os agentes de saúde envolvidos, tornando premente a procura de novas respostas para novas formas de vulnerabilidade e desigualdade na saúde, causadas pelo envelhecimento da população, pela pobreza, pela condição de género, pela etnicidade e pela desigual distribuição do conhecimento e acesso aos serviços de saúde.

12 A este cenário global não é de todo alheio o aparecimento de novos agentes, recursos e orientações políticas, novas formas de contratualização na gestão da saúde das populações e novas tecnologias de comunicação e de informação que, seguramente, irão introduzir alterações significativas nas relações entre as profissões de saúde e os doentes, assim como novas dinâmicas sociais associadas a novas formas de protagonismo leigo, e aos saberes e racionalidades que as subscrevem, tendo inúmeras pesquisas já sublinhado a eficácia material e simbólica que, por exemplo, estão na base da construção de itinerários terapêuticos alternativos e trajetórias sociais informais no acesso a cuidados de saúde (Carapinheiro, 2002a), do aumento significativo das associações dos doentes, da pertinência participativa das associações dos utentes e do vigor dos movimentos cívicos para a saúde.

Quer dizer que a pesquisa em saúde se confronta com determinantes estruturais, organizacionais, profissionais e sociais, em que as culturas em saúde estão em movimento, novos atores com formas de ação alternativas estão a emergir e a consciência do direito à participação deliberativa ganhou uma acuidade sem precedentes (Carapinheiro, 2010).

14 E porque comecei por aqui? Precisamente pelos desafios que cada uma das questões enunciadas levanta à pesquisa em saúde produzida pelas ciências sociais e humanas que, em termos metodológicos, reclamam a resistência aos postulados da objetividade cega e acrítica, confinados às velhas cartilhas dos requisitos lógicos e operativos de colocar em ação técnicas de pesquisa, frequentemente impondo aos pesquisados "modelos prefabricados" de os observar, documentar, inquirir, entrevistar e interpretar, sem sensibilidade às representações, identidades, subjetividades e reflexividades que estão em jogo em cada um deles. As configurações individuais, culturais e contextuais variáveis aqui presentes não os reúnem fatalmente em categorias homogéneas e internamente unificadas de conhecimento, nem os coloca inevitavelmente dentro dos limites dos processos de questionamento previamente organizados, como daria tanta satisfação e gáudio aos pesquisadores.

15 As pesquisas são também lugares da desordem, que nos esforçamos por controlar, desorganizando e reorganizando os pressupostos inicialmente traçados, impulsionando deslocamentos teóricos incessantes e, por vezes, até desesperantes, repensando e reavaliando todas as convicções epistemológicas consideradas inabaláveis e indestrutíveis, até porque a evidência empírica anteriormente produzida, justamente pela natureza intrínseca do seu caráter provisoriamente acabado, posteriormente parece poder garantir um elevado grau de previsibilidade de sucesso, que urge alcançar (Carapinheiro, 2002b).

16 Como podem ruir arquiteturas tão bem pensadas, preparadas e consignadas pela confiança inabalável dos métodos e das técnicas anteriormente utilizados? Como romper com processos de validação que tanta segurança prometiam? Como ousar rejeitar a legitimidade política adquirida pelos usos dos resultados das pesquisas já realizadas? Como evitar o "piscar de olho" das instâncias de financiamento, para que aqueles sejam os resultados e não sejam outros, os que não vimos, os que esquecemos, 
os que ocultámos e os que forçavam a rever e a reformular toda a pesquisa ou programa de pesquisa?

Ciência é poder e a Medicina é um dos seus mais poderosos dispositivos de conhecimento no que tange às matérias da saúde (Carapinheiro, 2006),

porque se apresenta caucionada pelas autoridades médicas e de saúde, de âmbito local, nacional, internacional e global,

porque ainda é o lugar central de produção dos mitos que estruturam as nossas crenças no tratar e no curar,

porque permanece como instância consagrada de reconhecimento da identidade biológica, individual e coletiva, como mapa fundador da simbólica organicista, porque nela se abrigam todas as normas jurídicas, sociais, morais, éticas e deontológicas que fundaram o pressuposto do funcionamento da ordem biológica como ordem social, e

porque a matriz dos saberes das múltiplas ciências que nela convergem estão oficialmente autorizados a realizar todas as formas de escrutínio do corpo.

Ou seja, do nascimento à morte, interiorizamos a imprescindibilidade da sua presença, como matriz científica, como profissão e como instituição. Socializamo-nos e ressocializamo-nos nas suas controvérsias (exemplo: o tratamento da menopausa), nas suas visões (exemplos: a saúde como oposto da doença; o normal como oposto do patológico), nas suas obstinações (exemplos: a pressão para a fertilidade humana, para a maternidade biológica, para a medicalização do parto, para a ideologização do aleitamento materno) e nas suas invenções (exemplos: a infância, a adolescência; as hormonas de crescimento; a hiperatividade como doença).

24 A prática da epistemologia crítica, sensível e cética ao complexo cognitivo de todas estas teorias, crenças, representações e visões, exige a mobilização de um processo de desconstrução, árduo e diligente, de colocação dos planos de análise que permitem fazer o debate das implicações decorrentes destas assunções.

Um dos planos de análise, de elevado potencial analítico para a contraposição da definição médica do que é saúde e doença, é a consideração destas realidades como sendo configuradas por dimensões políticas, económicas, culturais, morais, éticas e estéticas, pondo em relevo a necessidade de as colocar na ordem do mundo e da sociedade (Carapinheiro, 2011a). Quer dizer que, independentemente das fenomenologias biológicas e fisiológicas constitutivas das suas realidades médicas e clínicas, saúde e doença podem ser consideradas mapas simbólicos reveladores das estruturas políticas, sociais e culturais que lhes dão significado e sentido, implicados em múltiplos regimes de regulação, a que corresponde o estabelecimento de fronteiras morais que apoiam o processo de categorização e etiquetagem das doenças, a partir do funcionamento do modelo binário que, por exemplo, opõe doenças decentes a doenças indecentes; doenças vergonhosas a doenças moralmente aceitáveis; doenças puras a doenças impuras; doenças polutas a doenças impolutas; doenças limpas a doenças sujas (Sontag, 1998; Herzlich e Pierret, 1984; Douglas, 1966), mas também a consideração das suas condições estéticas, em função dos padrões dominantes de beleza e fealdade (os corpos e as suas deformações, as suas incapacidades, as suas excrescências, os seus artefactos e as suas monstruosidades (Ieda Tucherman, 2004), e ainda a partir de complicados dispositivos de ordenação ética da experiência de ter saúde ou estar doente. 

que os movem, vem a propósito referir que a análise feita neste plano só se completa e ganha eficácia quando a este se junta um outro que, contrariando todos os saberes convencionados de caráter político-administrativo dos organismos que asseguram a tutela da gestão da saúde no mundo, com base na compressão global do "estado de saúde" e do "estado de doença" a estados absolutos e universais (como é o caso da definição de saúde da Organização Mundial de Saúde), se propõe o "estado de não saúde" e o "estado de não doença" como uma proposta analítica com sede nas ciências sociais e humanas (Gill e Twaddle, 1977; Pflanz e Keupp, 1977). A resistência geralmente oferecida a estes "conceitos geminados" equivale ao desmoronar das ideias mais arreigadas sobre o caráter inquestionável do papel da medicina nas sociedades modernas e contemporâneas, como ciência e como instituição social. A surpresa e a perplexidade iniciais que suscita esta proposta conceptual residem exatamente no que menos se pode discutir e, principalmente, romper. Como pôr em causa o pensamento dicotómico que consagra a separação da saúde e da doença em territórios de racionalidade opostos? Com que direito se transgride as condições científicas historicamente estabelecidas sobre a desejabilidade individual e coletiva da saúde? Direito e dever de saúde unem-se num nó ideológico inextrincável que não admite oposição, desobediência, transgressão e desvio, e é exatamente porque o estado de não saúde e o estado de não doença admitem uma ampla margem de autonomia, de livre-arbítrio, de autorreflexividade nas escolhas de vida e de saúde, que aqui se faz sentir a normatividade dominante da defesa intransigente das fronteiras que os separam entre si, e, ao fazê-lo, produzem o mesmo efeito sobre outras entidades, como o normal e o patológico, a ordem e a desordem, o natural e o social, o racional e o irracional, a razão e a emoção, entre outras.

o desafio é este: trata-se de clarificar os termos da problematização quanto ao estatuto conceptual e analítico destes estados considerados ilegítimos, o que equivale a revelar que as referências humanas para a organização da vida, da saúde e da construção da realidade corpórea de cada um não se reduzem exclusivamente às da medicina e às de todas as formas de "especialismo" do saber médico, que difundem recomendações, orientações, guias de conduta, manuais de aconselhamento, medidas de prevenção, ampliando a intervenção médica aos objetivos de "aconselhar", de "guiar", de "educar", de "prever", de "gerir" e de "acompanhar", dilatando e reforçando os limites da sua vigilância e controlo, na exata medida do crescimento das suas contingências, incertezas e indeterminações.

As controvérsias e os dilemas éticos que decorrem da derrogação do estatuto legítimo das escolhas individuais em matéria de saúde e de doença e, portanto, da recusa da diluição da fronteira entre "estilos de vida saudáveis e não saudáveis" têm estado na origem de uma vasta literatura orientada para o resgate do domínio da experiência humana face aos constrangimentos sociais e condicionamentos normativos que a pretendem disciplinar.

Trata-se da tendência identificada por vários autores de a alçada da jurisdição médica incluir um número cada vez maior e mais diversificado de problemas; de continuar a reclamar uma ação profissional autónoma, sujeita ao exercício da sua exclusiva regulação; e de tentar conservar a sua posição de dominância profissional na organização da divisão do trabalho médico, colocando as outras profissões na posição de dependência e subalternidade (Stacey e Homans, 1978). 
31 O fascínio pelas tecnologias médicas para a resolução dos problemas de saúde revela um outro importante plano de análise, que propõe a desocultação da construção de sistemas de poder à volta das tecnologias médicas para a produção de cuidados médicos de alta complexidade, articulando-se-lhes processos de desigualdade social no acesso a cuidados de saúde, de caráter estratégico, que estas tecnologias disponibilizam. Tratase do fenómeno das "tecnocracias médicas", que se produzem maioritariamente nas práticas médicas hospitalares (Serra, 2008).

Aqui novos desafios se colocam à pesquisa, já que resultam do acionamento de dinâmicas articuladas a saberes profissionais hiperespecializados, de difícil acesso e apreensão, porque não acantonados num único lugar, pelo contrário, dotados de uma ampla transversalidade. As investigações realizadas demonstram que quando as tecnologias (vistas num sentido amplo, abarcando equipamentos, conhecimentos e competências profissionais específicos, recurso a múltiplas especialidades médicas, condições espaciais e temporais particulares) são raras e são inovadoras na inauguração de práticas médicas especializadas e hiperespecializadas, que estão na base de novas formas de reforço do prestígio e autoridade médicos, geram-se processos de organização de sistemas de poder que se alojam nas organizações de saúde, e que por elas são aceites, pelos efeitos reprodutivos que o poder destes sistemas manifesta possuir sobre o poder da organização. Mas, tanto a montante, como a jusante, surgem novas configurações de desigualdade social. A montante, nem todos os profissionais capacitados podem participar, ou seja, existem conflitos inter e intraprofissionais e disputas entre várias especialidades médicas que concorrem para a demonstração do caráter único dos seus conhecimentos e competências na luta pelo acesso a esse aparelho médico de poder e às suas condições excecionais de trabalho (no sentido dos desafios que colocam aos saberes profissionais), onde nem todos podem ficar. A escolha é autorregulada, ficando, portanto, fora da alçada dos mecanismos de controlo da organização. A jusante situam-se todos os processos de seleção dos doentes que podem usufruir da especialização destes cuidados médicos que, passando predominantemente pelo exercício do escrutínio médico, abre espaço a potenciais formas de discriminação e exclusão sociais.

Este exercício de reflexão é particularmente útil porque, independentemente das características fascinantes da operatividade destas tecnologias para curar doenças e salvar vidas, revela-se a sua não neutralidade aos valores e aos interesses dos projetos de poder das profissões, tanto mais determinantes quanto se apoiam em conhecimento muito codificado, não protocolado e insuscetível de gerar rotinas. Por outro lado, é possível interpretar melhor o mundo das organizações de saúde e da sua íntima relação com os fenómenos de poder, compreendendo como não estão dissociados de processos de categorização dos doentes que, podendo à primeira vista parecer ser de natureza estritamente clínica, no fundo acabam por ser principalmente de caráter social.

À medida que as diversas realidades da saúde e da doença se vão alargando e expandindo, também as aproximações científicas às biografias individuais de as construir e viver, e às organizações e instituições sociais a quem cabe a tutela de as vigiar, controlar e regular, se tornam cada vez mais difíceis, complexas e problemáticas. Tal raciocínio radica num aparente entendimento tácito, que se supõe ser compreendido consensualmente e sem equívocos, de que estão bem definidos pelas ciências da saúde, designadamente pela medicina, os limites da intervenção das ciências sociais, quanto ao facto de ambas se ocuparem da explicação, não de um 
mesmo mundo, mas de dois, incompatíveis e irreconciliáveis, e, por isso mesmo, as respetivas lógicas e racionalidades não podem ser transpostas de um campo científico para o outro e não devem transcender a exclusividade dos seus respetivos dispositivos de funcionamento.

Sendo assim, prescreve-se que cada ciência deve saber ocupar o seu lugar e reconhecer o ordenamento normativo das suas possibilidades legítimas, segundo as prescrições deontológicas que devem definir os horizontes éticos, assim como se recomenda que cada um deve interpretar o seu papel nesse lugar, de forma a acautelar eventuais infrações aos códigos morais, ao ethos de cada disciplina, para saber preservar a dignidade do estatuto humano dos sujeitos envolvidos (investigadores e investigados) e para defender a dignidade da ciência.

37 Tais posições e respetivos postulados, independentemente da maior ou menor razoabilidade moral que os sustenta, não equacionam a posição de cada ciência nas hierarquias informais de poder, nem consideram as consequências que decorrem do caráter hegemónico e desregulado do seu exercício, nas múltiplas configurações que vai assumindo nos campos científico, institucional e profissional. É nesta omissão que se forjam diferentes estratégias de resistência, confrontação e repressão à intervenção de outras ciências, ocultando a existência de outros agentes de conhecimento, desvalorizando as suas agendas e prioridades de investigação e excluindo a expressão legítima dos seus enunciados éticos.

Estas considerações conduzem-nos à definição dos contornos políticos da ética e dos contornos éticos da política, quer na investigação científica em geral, quer na investigação em saúde em particular. Neste caso, a saúde e a doença são realidades multidimensionais com crescente complexidade científica, amplitude experiencial e amplificação social, que se estendem ao plano global. Na medida das controvérsias científicas que se erguem sobre como interpretar e reinterpretar os estados de saúde e de doença nas sociedades contemporâneas, também se geram novos desafios e dilemas éticos relativamente às suas implicações na vida individual e coletiva. No âmbito dos contornos acima mencionados, colocam-se inevitavelmente novas interrogações normativas e emergem novos horizontes de problemas morais, se pensarmos que a investigação em saúde requer necessariamente uma colocação ética centrada no sofrimento do sujeito humano e na saúde como direito humano inalienável.

39 Faz parte desta colocação a proteção dos sujeitos de investigação, garantindo o consentimento informado, a confidencialidade e a privacidade, no seu acesso a todas as condições objetivas e subjetivas que tecem o seu quotidiano em todos os contextos onde se desenrolam a prestação de cuidados de saúde. Respeita-se a sua particular condição de vulnerabilidade e fragilidade, que os torna um alvo fácil de vários processos de exploração desta condição. Cumprem-se as normas e os regulamentos institucionais quanto à presença do investigador, desde as autorizações concedidas, aos espaços e às formas de contacto e à determinação dos tempos de permanência.

Mas, apesar de todas as orientações éticas produzidas, os investigadores das ciências sociais confrontam-se com crescentes dificuldades no acesso às instituições de saúde, na obtenção das autorizações das suas comissões de ética, na apreciação intrusiva e ilegítima que aí se faz das suas propostas de estudo, na imposição de modelos de abordagem metodológica inadequados aos objetivos de estudo, na distorção dos propósitos da investigação, carregados de suspeição e desconfiança, pondo em causa o rigor e a qualidade do estudo, investindo no efeito de saturação psicológica dos 
investigadores e pondo em causa a viabilidade dos compromissos assumidos, face às instituições de pertença e às instituições de financiamento.

Até que ponto não se justificará fazer a análise crítica da ética da investigação, como problemática em aberto, capaz de revelar o que se oculta nas racionalidades dos atores que as praticam? Porque não considerar a ética como um campo de poderes e contrapoderes, de onde poderão emergir novas formas de negociação entre os vários ethos em presença? E será que não valerá a pena inovar os termos da prática científica, criando novos agentes de avaliação ética, inaugurando processos de redefinição dos modelos de avaliação e gerando reflexão ético-política inovadora sobre as suas implicações (Carapinheiro, 2011b)? Nesta proposta reside, em grande medida, a ideia das paridades periciais, como sinónimo de democracia científica, de cidadania ativa e participativa do sujeito da ciência no mundo e do estabelecimento de novos vínculos, geradores de novos compromissos ético-políticos a inventar.

\section{BIBLIOGRAFIA}

CARAPINHEIRO, Graça (2002a), “O método de pesquisa de terreno. A aproximação ao campo e aos informantes" in F. J. Mercado, D. Gastaldo e C. Calderón (Orgs.), Investigación cualitativa en salud en Iberoamérica. Métodos, análisis y ética, Guadalajara, Universidad de Guadalajara, Servicio Vasco de Salud-Osakidetza.

CARAPINHEIRO, G. (2002b) “Inventar percursos, reinventar realidades: doentes, trajectórias sociais e racionalidades formais", Etnográfica, Vol. V (2).

CARAPINHEIRO, G. (2005), "Do Bio-Poder ao Poder Médico", Estudos do Século XX - Ciência, Saúde e Poder, Centro de Estudos Interdisciplinares do Século XX (CEIS20), n.o 5.

CARAPINHEIRO, G. (2006), “A saúde enquanto matéria política”, in G. Carapinheiro (org.), Sociologia da Saúde: Estudos e Perspectivas, Coimbra, Editora Pé de Página.

CARAPINHEIRO, G. (2007), "Saúde e risco na sociedade portuguesa: para uma nova agenda das políticas da vida" in J. M. L. Viegas, H. Carreiras, e A. Malamud (orgs.), Portugal no Contexto Europeu vol. I, Instituições e Política, Oeiras, Celta Editora.

CARAPINHEIRO, G. (2010), "Equidade, Cidadania e Saúde. Apontamentos para uma Reflexão Sociológica”, Alicerces, Edição do Instituto Politécnico de Lisboa, Ano III, n.․․ 3.

CARAPINHEIRO, G. (2011a), "Saúde e Doença: um programa crítico de sociologia da saúde", Sociologia on Line, Revista da Associação Portuguesa de Sociologia, n. 3 (temático: Encontro Nacional de Sociologia da Saúde: Práticas em Debate).

CARAPINHEIRO, G. (2011b), “Investigação e Regulação Ética: controvérsias e paridades periciais”, Sociologia on Line, Revista da Associação Portuguesa de Sociologia, n. 3 (temático: Encontro Nacional de Sociologia da Saúde: Práticas em Debate).

DOUGLAS, M. (1980), Purity and Danger: an analysis of the concept of pollution and taboo, Londres, Routledge. 
GILL, D. e A. Twaddle (1977), "Medical Sociology: What's in a Name”, International Social Science Journal, 29 (3), pp. 369-385.

HERZLICH, C. e J. Pierret (1984), Malades d'Hier, Malades d'Aujourd'hui. De la mort collective au devoir de guérison, Paris, Payot.

LOPES, N. M. (2010), Medicamentos e Pluralismo Terapêutico. Práticas e Lógicas Sociais em Mudança, Porto, Edições Afrontamento.

MENDES, F. (2007), Futuros Antecipados: para uma sociologia do risco genético, Porto, Edições Afrontamento.

PFLANZ, M. e H. Keupp (1977), “A Sociological Perspective on Concepts of Disease”, International Social Science Journal, Vol. XXIX, n.ำ 3, pp. 386-397.

SACKETT, D. L.; W. C. Rosenberg; J. A. Muir Gray; R. B. Haynes; W. S. Richardson (1996), "Evidence based medicine: what it is and what it isn't", BMJ (312), 71-2.

SERRA, H. (2008), Médicos e Poder. Transplantação Hepática e Tecnocracias, Lisboa, Livraria Almedina.

SONTAG, S. (1998), A Doença como Metáfora e a Sida e as suas Metáforas, Lisboa, Quetzal, Col. Serpente Emplumada.

STACEY, M. e H. Homans (1978), “The Sociology of Health and Illness: Its present state, future prospects and potential for health research", Sociology, n.․12, pp. 281-307.

TUCHERMAN, I. (2004), Breve história do corpo e de seus monstros, Lisboa, Quetzal, Col. Serpente Emplumada, 2. edição.

\section{NOTAS}

1. Comunicação apresentada no V Congresso Ibero-Americano de Pesquisa Qualitativa em Saúde - Circulação de Saberes e Desafios em Saúde, realizado em Lisboa entre 11 e 13 de Outubro de 2012.

\section{RESUMOS}

Este texto resulta do convite que me foi dirigido para fazer a conferência de abertura do $\mathrm{V}$ Congresso Ibero-Americano de Pesquisa Qualitativa em Saúde, subordinado ao tema "Circulação de Saberes e Desafios em Saúde".

Pretendi situar-me no centro das problemáticas suscitadas pelo tema do congresso e desenvolver um conjunto de reflexões que permitissem deslocar os "desafios" do terreno da produção das práticas para o campo da produção dos saberes, a partir de um isolamento analítico meramente provisório, mas que pudesse iluminar de alguma forma os segredos e os enredos da investigação em saúde.

Com este movimento breve abriu-se espaço para analisar a amplitude e a complexidade dos aspetos que se prendem com a relação entre as ciências da saúde e as ciências sociais e humanas, 
conferindo particular importância aos contornos que têm assumido os seus "encontros" ao longo do tempo, a partir das suas tradições intelectuais, culturas científicas e inserções institucionais.

This text comes from the invitation to make the opening conference of the $5^{\text {th }}$ Ibero-American Congress of Qualitative Health Research, entitled "Movements of Knowledge and Challenges in Health."

My purpose was to place myself in the center of the issues raised by the conference theme and develop a set of reflections that would allow the moving of the "challenges" from the production of practices to the field of knowledge production, in a purely analytical provisional isolation, but that would somehow illuminate the secrets and plots of health research.

With this brief move a space opened up to analyze the breadth and complexity of issues pertaining to the relationship between the health sciences and the humanities and social sciences, which stressed the contours that have taken their "meetings" over time, derived from its intellectual traditions, scientific cultures and institutional positions.

\section{ÍNDICE}

Keywords: health/illness, critical epistemology, health research

Palavras-chave: saúde/doença, epistemologia crítica, investigação em saúde

\section{AUTOR}

\section{GRAÇA CARAPINHEIRO}

Professora Catedrática no Departamento de Sociologia do ISCTE-IUL/Instituto Universitário de Lisboa e Investigadora do CIES/ISCTE-IUL (graca.carapinheiro@iscte.pt) 